\title{
Interventions to improve the mechanical ventilation fidelity of the Laerdal SimMan® 3G simulation mannequin
}

\author{
Neil J. Mehta, MD - Renee Latoures, RN, MS - Martin M. Stechert, MD, PhD • \\ Richard L. Fidler, PhD, CRNA, NP, MBA · Jan Hirsch, MD, PhD
}

Received: 11 August 2017/Revised: 4 December 2017 / Accepted: 4 December 2017/Published online: 14 December 2017

(C) Canadian Anesthesiologists' Society 2017

\section{To the Editor,}

The Laerdal SimMan® 3G mannequin (Laerdal USA, Wappingers Falls, NY, USA) is widely used for highfidelity simulation. Nevertheless, providers familiar with mechanical ventilators commonly notice a lower lung compliance, necessitating lower set tidal volumes $\left(\mathrm{V}_{\mathrm{T}}\right)$ to reduce airway pressure. SimMan $3 \mathrm{G}$ is $180 \mathrm{~cm}$ tall, which corresponds to an ideal body weight of $75 \mathrm{~kg}$ (according to http://www.ardsnet.org/tools.shtml) and a $\mathrm{V}_{\mathrm{T}}$ of $600 \mathrm{~mL}$ at $8 \mathrm{~mL} \cdot \mathrm{kg}^{-1}$. This "normal" $\mathrm{V}_{\mathrm{T}}$ without positive endexpiratory pressure (PEEP) results in a peak airway pressure of $34 \mathrm{cmH}_{2} \mathrm{O}$. For a $\mathrm{V}_{\mathrm{T}}$ of $500 \mathrm{~mL}$, the peak airway pressure was $28 \mathrm{cmH}_{2} \mathrm{O}$ and the static airway compliance was $24 \mathrm{~mL} \cdot \mathrm{cmH}_{2} \mathrm{O}^{-1}$. This static airway compliance of the stock mannequin is about $30-50 \%$ of typical human values. ${ }^{1}$ These values are reproducible among six SimMan 3G mannequins to which our group has access. Adding PEEP exacerbates problems with highpressure alarms, and a PEEP above $5 \mathrm{cmH}_{2} \mathrm{O}$ and $\mathrm{V}_{\mathrm{T}}$ of $500 \mathrm{~mL}$ results in an air leak greater than $2 \mathrm{~L} \cdot \mathrm{min}^{-2}$ (ventilator bellows cannot be driven with $2 \mathrm{~L} \cdot \mathrm{min}^{-1}$ flow).

The high peak airway pressures and air leak are frequently noticed in simulation sessions for maintenance of certification in anesthesia done for the American Board of Anesthesiology. High airway pressures may mislead participants by suggesting acute lung injury, endotracheal tube kinking, or a mucus plug. This causes trainee

N. J. Mehta, MD $(\bowtie) \cdot R$. Latoures, RN, MS .

M. M. Stechert, MD, PhD - R. L. Fidler, PhD, CRNA, NP, MBA · J. Hirsch, MD, PhD

Simulation Center and Anesthesia Service, San Francisco VA

Medical Center and University of California San Francisco, San

Francisco, CA, USA

e-mail: neilmehta83@gmail.com confusion and frequent intervention and interruption by the simulation team, making it difficult for participants to be fully engaged in the scenario. ${ }^{2}$ To circumvent these problems, we investigated fitting larger, more elastic reservoirs (Rusch 500-mL ventilator test lungs) inside the mannequin. The stock Laerdal SimMan ${ }^{\circledR} 3 \mathrm{G}$ mannequin has 350-mL reservoir bags (part 212-11150). We also attached satellite reservoirs (Siemens Maquet ventilator test lungs; Maquet, Rastatt, Germany) with a Y connector to the circuit outside the mannequin. A third modification was to extend the internal connection tubing to avoid disconnections.

Replacement of the stock reservoirs (Figure A) inside the mannequin with a 500-mL Rusch ventilator test lung (Teleflex, Wayne, PA, USA) (Figure B) resulted in higher fidelity in $\mathrm{V}_{\mathrm{T}}$, peak airway pressure, and calculated compliance. ${ }^{3,4}$ For a $500-\mathrm{mL} \mathrm{V}_{\mathrm{T}}$, peak airway pressure was $12 \mathrm{cmH}_{2} \mathrm{O}$ and static compliance was 50 $\mathrm{mL} \cdot \mathrm{cmH}_{2} \mathrm{O}^{-1}$.

The fitting of an external "satellite" bag (Figure D) was done with 250-, 500-, and 1000-mL Siemens Maquet ventilator test lungs. Using the $1000-\mathrm{mL}$ bag and a $500-\mathrm{mL}$ $\mathrm{V}_{\mathrm{T}}$, peak airway pressure was $8 \mathrm{cmH}_{2} \mathrm{O}$ and static compliance was normal at $83 \mathrm{~mL} \cdot \mathrm{cmH}_{2} \mathrm{O}^{-1}$. Additionally, we were able to achieve a PEEP of 15 $\mathrm{cmH}_{2} \mathrm{O}$ and a $\mathrm{V}_{\mathrm{T}}$ of $400 \mathrm{~mL}$ without high pressure alarms (peak airway pressure was $38 \mathrm{cmH}_{2} \mathrm{O}$ ).

High airway pressures combined with chest compressions in simulation scenarios contribute to frequent tubing disconnects and ventilation reservoir ruptures. Replacement of the internal connection tubing with a longer piece of tubing and stronger cable ties abolished further occurrences of tubing disconnect (Figure C). 
Exchange of the lungs with Rusch test lungs required one to two hours of work and minimal cost, was reversible, and was invisible to participants. After exchange, the possibility to adjust resistance and compliance with the mannequin controls was partially preserved. Nevertheless, modifying the mannequin does compromise the manufacturer's warranty. This can be avoided by attaching a satellite ventilator test bag externally to the circuit, resulting in physiologic values for compliance. Unfortunately, resistance and compliance of the satellite lungs cannot be adjusted by the mannequin software.

These interventions enhance the fidelity of the SimMan 3G mannequin for mechanical ventilation substantially. This expands the usability of the mannequin to more
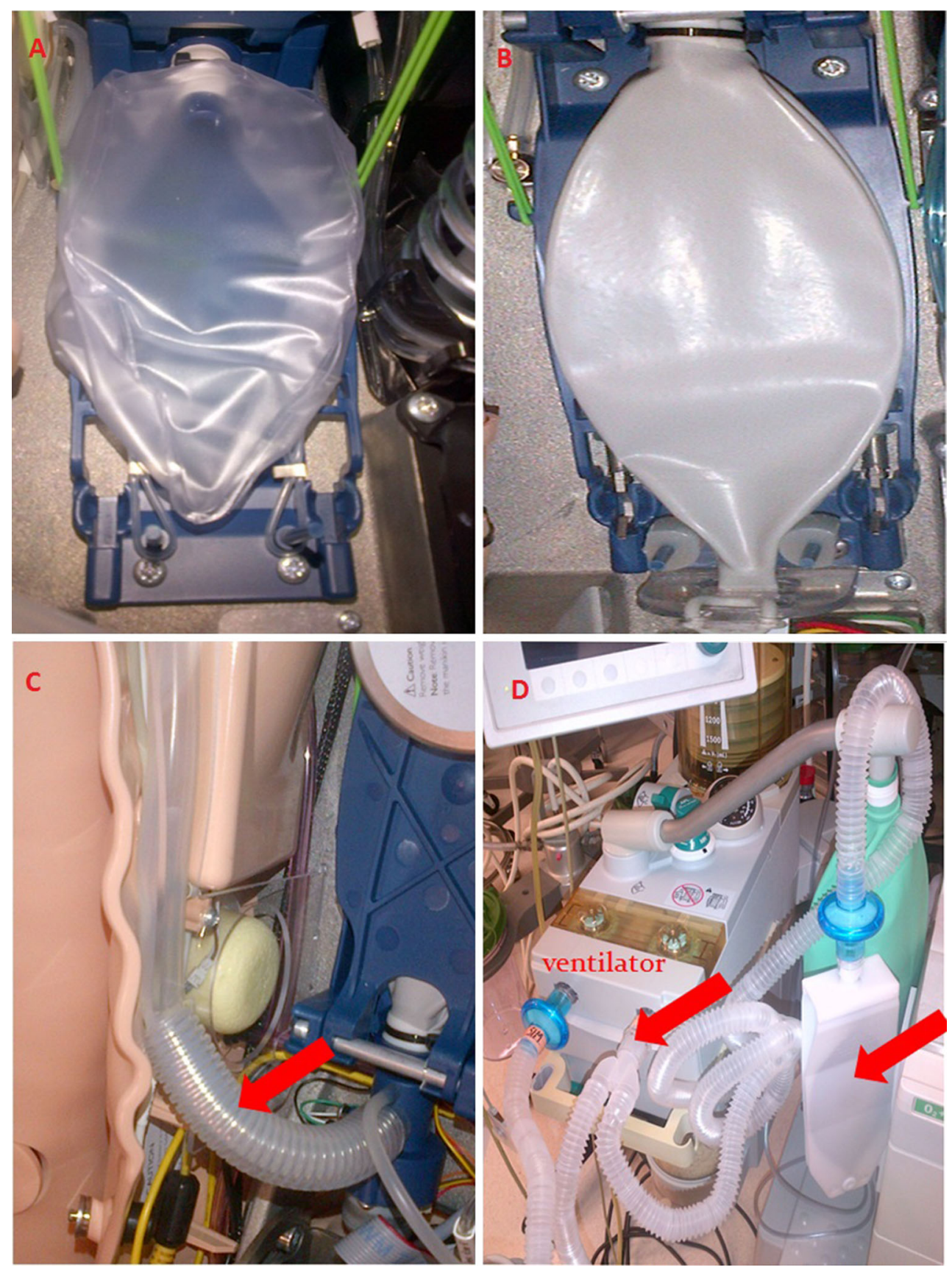

Figure Mannequin modifications to improve mechanical ventilation fidelity A) The stock Laerdal SimMan ${ }^{\circledR} 3 \mathrm{G}$ mannequin has $350-\mathrm{mL}$ reservoir bags, part 212-11150. B) Modification of the Laerdal SimMan ${ }^{\circledR}$ 3G mannequin with 500-mL Rusch ventilator test lungs,

which are more elastic. C) Modification of the Laerdal SimMan ${ }^{\circledR}$ 3G mannequin with a longer piece of internal connection tubing (red arrow) and stronger cable ties. D) Fitting of external "satellite" Siemens Maquet ventilator test lungs to the ventilator 
advanced and specialized participants and improves its reliability.

Conflict of interest There are no conflicts of interest for any of the authors to disclose.

Disclosure There are no other associations to disclose.

Editorial responsibility This submission was handled by Dr. Hilary P. Grocott, Editor-in-Chief, Canadian Journal of Anesthesia.

Funding There are no external funding sources to disclose.

\section{References}

1. Haenel JB, Johnson JL. Mechanical Ventilation in Critical Illness. In: Duke J (Ed.). Anesthesia Secrets, $4^{\text {th }}$ ed. Mosby; 2011: 149-16.

2. Meurling L, Hedman L, Lidefelt KJ, Escher C, Fellander-Tsai L, Wallin CJ. Comparison of high- and low equipment fidelity during paediatric simulation team training: a case control study. BMC Med Educ 2014; 14: 221.

3. Hess DR. Respiratory mechanics in mechanically ventilated patients. Respir Care 2014; 59: 1773-94.

4. Henderson WR, Sheel AW. Pulmonary mechanics during mechanical ventilation. Respir Physiol Neurobiol 2012; 180: $162-72$. 